\title{
O ENSINO REMOTO COMO METODOLOGIA ATIVA PARA O EMPREENDEDORISMO E A INOVAÇÃO NA EDUCAÇÃO BÁSICA
}

\author{
Elias Vieira de Paula ${ }^{1}$ \\ Everton Rangel Bispo ${ }^{2}$ \\ Kátia Eliane Santos Avelar ${ }^{3}$
}

RESUMO: A escola contemporânea tem procurado novas formas e modelos que venham dinamizar a aprendizagem em todos os seus segmentos. Dentre os novos modelos surge a metodologia ativa da educação que é a estratégia de dar ao aluno a autonomia e o protagonismo para a aprendizagem. Diante do grande índice de desemprego entre os jovens, caracterizado por diversos fatores da economia, este estudo teve por objetivo desenvolver uma ferramenta tecnológica destinada ao ensino do empreendedorismo e da inovação. $O$ aplicativo denominado "PROCOMECE" contém orientações, informações e conteúdos básicos necessários para a criação de um negócio. Os dados foram coletados por meio de um workshop presencial com perguntas acerca da relevância do App para estudantes da educação básica. Os resultados da pesquisa demonstraram que a utilização do aplicativo foi útil, não só como ferramenta com orientações, mas também, como instrumento de conhecimento, pois eles desconheciam as informações básicas para serem agentes de transformação local. A partir do uso do aplicativo perceberam a possibilidade de criação de um negócio com objetivo de solucionar problemas. Assim, concluiu-se que o desenvolvimento do aplicativo móvel atendeu as expectativas, pois serviu como ferramenta de orientação e informação para atuação dos estudantes da educação básica sendo protagonistas da aprendizagem.

Palavras-chave: Metodologia Ativa. Empreendedorismo. Educação

\footnotetext{
${ }^{\mathrm{I}}$ Mestrando em Desenvolvimento Local pelo Centro Universitário Augusto Motta, UNISUAM, Rio de Janeiro, RJ. E-mail: eliasvdepaula@gmail.com Orcid: https://orcid.org/oooo-ooor-6694-3157

${ }^{2}$ Doutor em Engenharia de Materiais e Processos Químicos e metalúrgicos pela PUC-Rio.Professor do centro universitário Augusto Motta. Pesquisador do programa Pós graduação em desenvolvimento Local do centro universitário Augusto Motta.Orcid: https://orcid.org/oooo-ooo2-0990-4992

3 Doutora em Ciências pela UFRJ. Pesquisadora em Desenvolvimento Tecnológico e Extensão Inovadora do CNPq. Docente e Pesquisadora do Programa de Pós-Graduação em Desenvolvimento Local no Centro Universitário Augusto Motta, UNISUAM, Rio de Janeiro, RJ.

E-mail: katia.avelar@gmail.com.Orcid: https://orcid.org/oooo-ooo2-7883-9442
} 
ABSTRACT: The contemporary school has been looking for new forms and models that will streamline learning in all its segments. Among the new models, the active methodology of education emerges, which is the strategy of giving the student autonomy and protagonism for learning. In the face of the high rate of unemployment among young people, characterized by various economic factors, this study aimed to develop a technological tool aimed at teaching entrepreneurship and innovation. The application called "PROCOMECE" contains guidelines, information and basic content necessary for creating a business. Data were collected through a face-to-face workshop with questions about the App's relevance for basic education students. The survey results showed that the use of the application was useful not only as a tool with guidelines, but also as an instrument of knowledge, as they were unaware of basic information to be agents of local transformation through the creation of a business with the objective of solving problems. Thus, it was concluded that the development of the mobile application met expectations, as it served as a guidance and information tool for basic education students to act as protagonists in learning.

Keywords: Active Methodology. Entrepreneurship. Education

\section{INTRODUÇÃO}

A escola contemporânea tem procurado novas formas e modelos que dinamizem a aprendizagem em todos os seus segmentos. Dentre os novos modelos surge a Metodologia Ativa da Educação que é a estratégia de dar ao aluno a autonomia e o protagonismo para a aprendizagem (DELIZOICOV; ANGOTTI; PERNAMBUO, 2009).

Esta autonomia para o aprendizado transforma o aluno em um empreendedor. O aluno empreende com liberdade em sua busca pelo conhecimento e inova a sua aprendizagem, configurando um modelo de metodologia ativa definida como o comentário abaixo:

Principalmente em virtude do cenário atual de nossa sociedade, que precisa de indivíduos pensando e agindo de forma crítica e reflexiva. Mas, para que essas competências possam ser atingidas no meio escolar, o ensino precisa caminhar para realizar a articulação entre os conteúdos e sua aplicabilidade. De forma, que seja possível desenvolver as habilidades nos estudantes, para que as competências sejam atingidas. Entretanto, esse fato torna-se viável apenas com uma nova maneira de abordar o ensino. (SEGURA, 2015. p.3). 
No vasto campo da metodologia ativa da educação apresento neste trabalho o estudo eletrônico do empreendedorismo e a inovação como oportunidade para que o aluno descortine possibilidades para a criação de soluções diante de problemas que afetam a sua vida. Tais soluções produzidas podem impactar positivamente o ambiente, a economia e a qualidade de vida, contribuindo para diminuição da vulnerabilidade social.

O ensino do empreendedorismo deve ser uma aérea de conhecimento, não somente relevante para os alunos de cursos superiores, mas também inserido no currículo de propostas de ensino da educação básica, que colabora na compreensão e no aperfeiçoamento da aprendizagem escolar. (ROCHA e FREITAS, 2014; MORAES et al, 2018).

Ainda que haja dificuldade de acesso à internet aos alunos de baixa renda, contudo o celular e o smartphone têm estado nas mãos da grande maioria dos estudantes, se tornando hoje o principal canal de comunicação para a sua vida. Com o advento do covid-19 o ambiente de estudo EAD e online que já vinham sendo estimulados como alternativa de uma nova sala de aula pelas instituições de ensino se fortaleceu e hoje o ensino híbrido já é uma realidade dentro da metodologia ativa da educação.

O método e-learning, que é o ensino remoto e ferramenta de educação online para a distribuição de pílulas de conteúdos foi elaborado pelo App PROCOMECE para a difusão de conhecimento aos estudantes da educação básica. Dessa forma obterão informações e aprendizado para o empreendedorismo e a inovação.

O App PROCOMECE, que é um laboratório virtual de inovação, proporcionará aos estudantes da educação o vislumbrar de um ambiente criativo e colaborativo, novos conhecimentos que podem ser facilmente compartilhados e propostas de trabalhos que podem ser desenvolvidos, criando assim novas possibilidades e expectativas de um futuro melhor.

O conceito de trilhas de aprendizagem já foi apresentado pelo autor em encontros presenciais através das oficinas de empreendedorismo contratadas pelo SESC RJ, e através da EVP Treinamentos, em o que o autor deste trabalho também é gestor. As trilhas de aprendizagem serão disponibilizadas pelo APP 
PROCOMECE, mediante acesso de ensino EAD. O estudante será um protagonista no desenvolvimento de suas competências e habilidades, mediante a criatividade, o pensamento crítico, a empatia, a visão sistêmica e a resiliência, entre outras, que são essenciais para a execução de ações empreendedoras sustentáveis e adequadas aos contextos de suas próprias comunidades e territórios.

\section{METODOLOGIA}

Trata-se de uma pesquisa com o objetivo de desenvolvimento de um aplicativo móvel para orientar e informar estudantes da educação básica sobre a criação de um negócio para solucionar problemas e servir como fonte de geração de renda.

A pesquisa que deu origem ao App PROCOMECE passou por três fases de desenvolvimento: A primeira, iniciada com artigo de revisão de literatura que abordou a necessidade de investimento de políticas públicas em tecnologia para a educação básica.

A segunda foi realizada em pesquisa virtual e presencial com os alunos da educação básica a respeito do conhecimento deles sobre o empreendedorismo e a inovação, e sobre o interesse acerca de acesso a um aplicativo com conhecimento pertinente a esta área.

A terceira, o desenvolvimento do App PROCOMECE pela empresa Atos6, com as funcionalidades de Doação Online, Aulas Online, Inscrições para eventos e aulas presenciais e onlines; Gestão de cursos e turmas; Acesso para a plataforma EAD, com gerenciamento de todas as etapas do evento e recebimento de inscrições; O App PROCOMECE está disponível nas lojas online do Google Play e App Store do Iphone.

\section{RESULTADOS E DISCUSSÃO}

Os participantes consideraram os conteúdos pertinentes e a linguagem de fácil entendimento. Validaram positivamente o ambiente virtual para a apresentação dos conteúdos e conhecimentos, conforme informações abaixo dos alunos de ensino médio 
Figura I - Amostra de Resultados

$\begin{array}{lllll}\begin{array}{l}\text { Respostas dos } \\ \text { Alunos }\end{array} & \text { Ótimo (\%) } & \text { Bom (\%) } & \text { Regular (\%) } & \text { Ruim (\%) } \\ \begin{array}{l}\text { Relevância do } \\ \text { conteúdo }\end{array} & (100 \%) & 0 \% & 0 \% & 0 \% \\ \begin{array}{l}\text { Identificação da } \\ \text { situação- } \\ \text { problema }\end{array} & (100 \%) & 0 \% & 0 \% & 0 \% \\ \begin{array}{l}\text { Contribuição } \\ \text { prática }\end{array} & (100 \%) & 0 \% & & 0 \% \\ \end{array}$

Elaborado pelo autor. 2021.

Com relação aos resultados os alunos participantes do workshop de apresentação do App PROCOMECE do segmento do ensino médio alegaram que embora tivessem interesse de abrir algum negócio não saberiam como iniciar por desconhecer o caminho e o processo na execução da ideia que geraria renda e causaria impacto socioambiental.

Todos os participantes, estudantes da educação básica informaram que ao longo de suas jornadas escolares não haviam sido estimulados para pesquisarem sobre conteúdos de aprendizagem de temáticas transversais em empreendedorismo. Compreendiam que este tipo de conhecimento é elitizado ou não apropriado para a idade e vivência deles.

Outro aspecto a considerar era a expectativa dos estudantes quanto à oportunidade de vaga de emprego mediante o avanço de seus estudos, limitado a esperança somente da conquista pela carteira assinada e não de se tornarem empreendedores.

O App foi testado por estudantes do ensino médio em evento realizado em na Primeira Igreja Batista da Fazenda Botafogo, devido à dificuldade de autorização 
para apresentação presencial e online do APP nas instituições de ensino, por conta da pandemia do covid-I9.

Participaram também da apresentação do APP os pais e responsáveis dos alunos de ensino médio que consideraram juntamente com o público-alvo a relevância do App PROCOMECE como instrumento de geração de renda e desenvolvimento local. O evento de apresentação pode influenciar também a instituição religiosa à promoção e lançamento de cursos de artesanato, moda, beleza e música para a população local como fator de aquecimento da economia criativa.

Para os alunos do $9^{\circ}$ do ensino fundamental foi realizado um Workshop na Escola Municipal Embaixador Barros Hurtado, bairro de Cordovil, Zona Norte do Município do Rio de Janeiro, quando participaram 49 alunos de idade de 14 a 17 anos, mediante aos seguintes resultados, após a apresentação conteúdo do App:

Figura 2 - Conhecimento sobre o significado de empreendedorismo e inovação

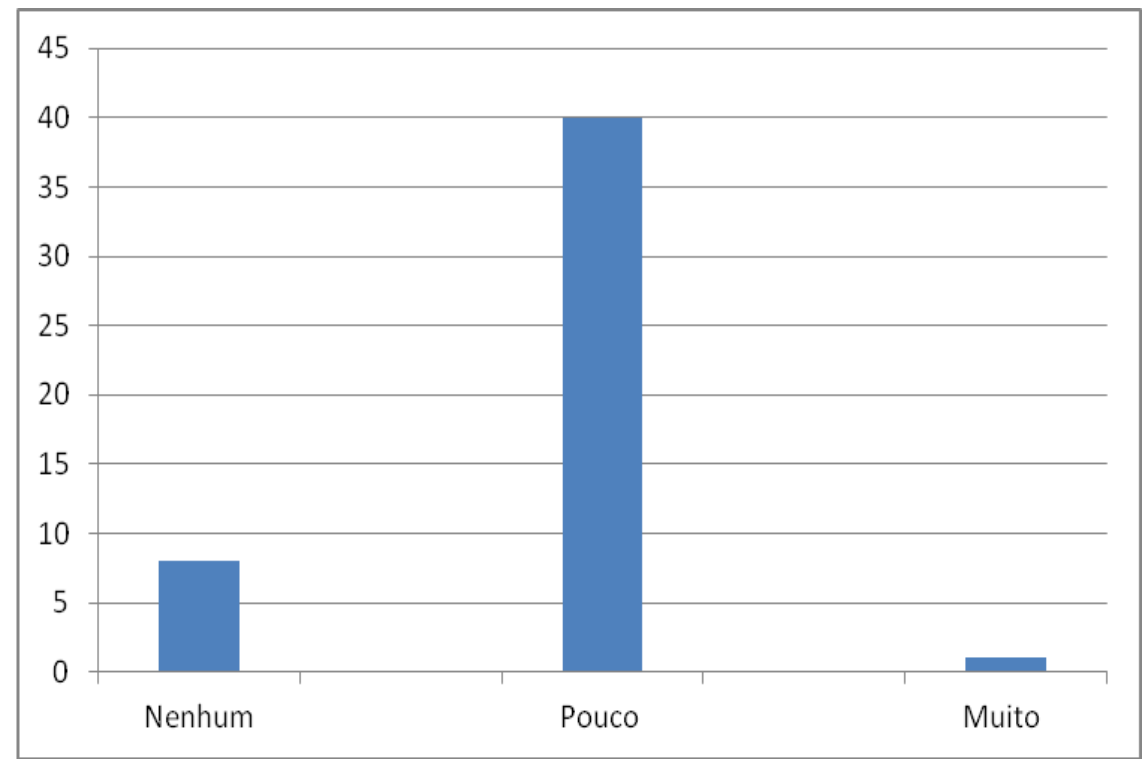

Fonte: Elaborada pelo autor, 2021.

A maioria dos alunos desconhecem o conceito e o significado do empreendedorismo e inovação. Este desconhecimento não possibilita pensar em alternativas atividades e trabalho, limitando-o a esperança de conquista de um emprego futuro como via única de geração de renda 
Figura 3 - Relevância da aprendizagem em empreendedorismo e inovação

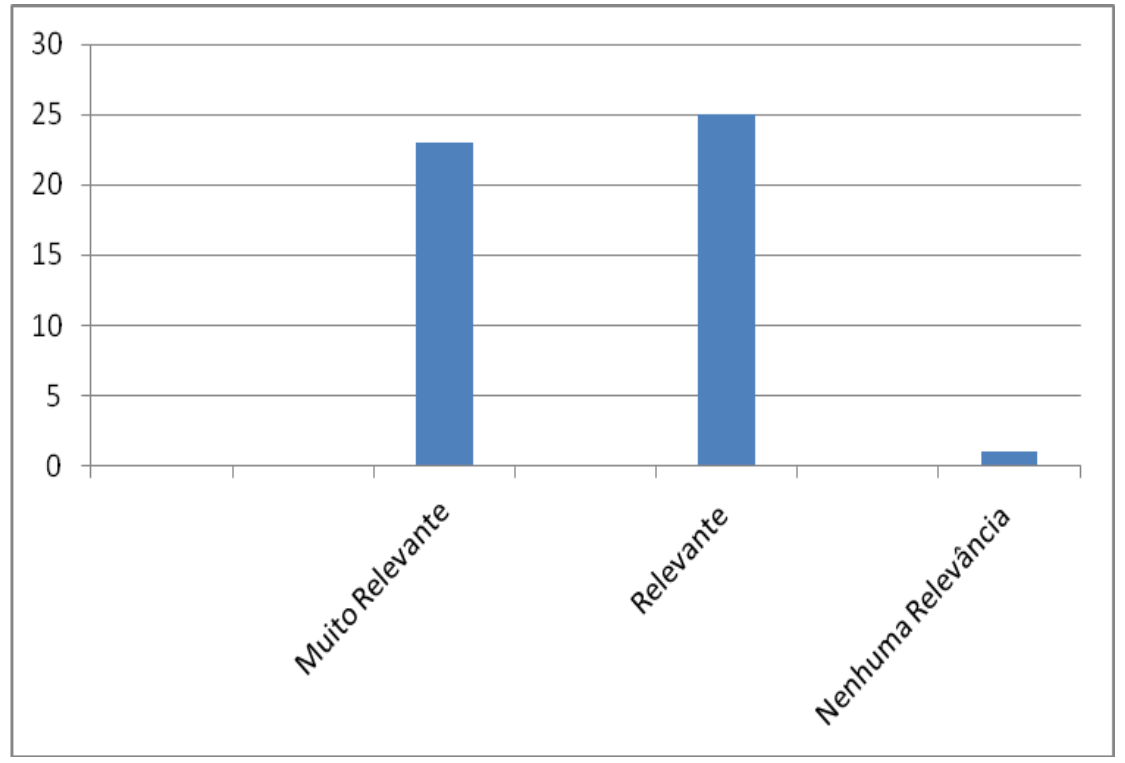

Fonte: Elaborada pelo autor. 2021.

Quanto a relevância do conteúdo apresentada pelo App para o conhecimento do empreendedorismo e inovação, os estudantes destacaram a importância das informações apresentadas pelo conteúdo.

Figura 4 - Desejo de tornar-se um empreendedor

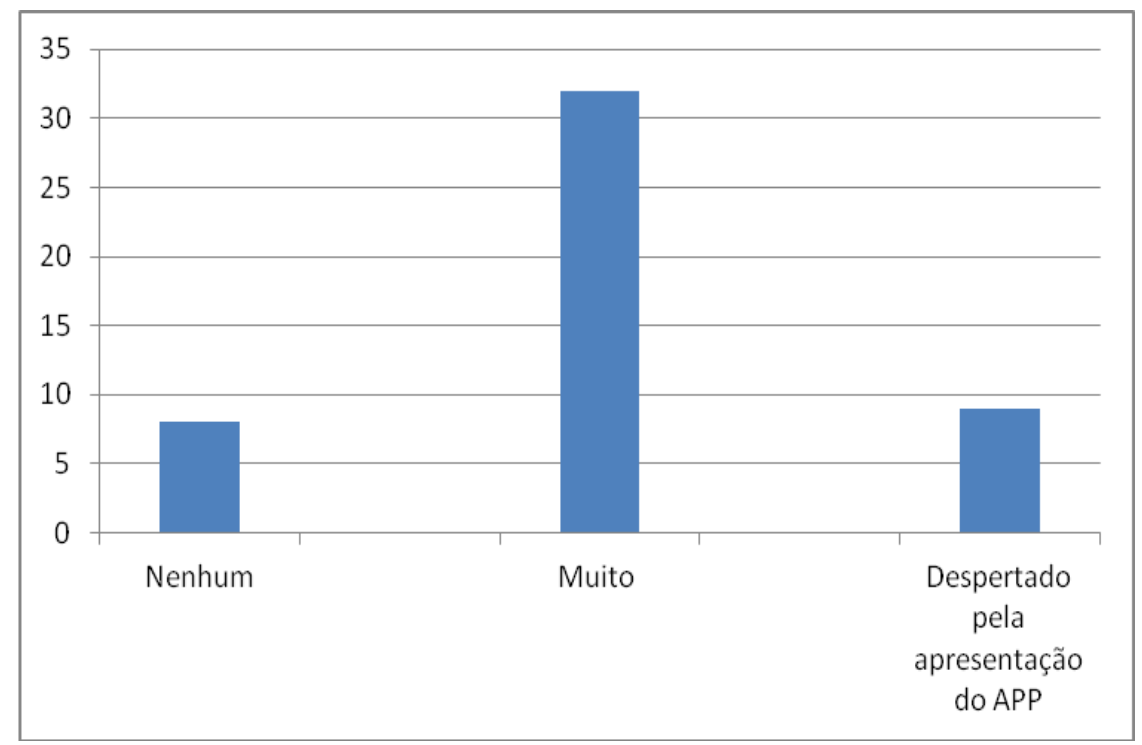

Fonte: Elaborada pelo autor. 2021.

Mesmo sem um conhecimento profundo sobre o empreendedorismo e a 
inovação, os alunos já sonham e imaginam ter a oportunidade de possuírem o seu próprio negócio.

Figura 5 - Compreensão sobre o conteúdo do App PROCOMECE

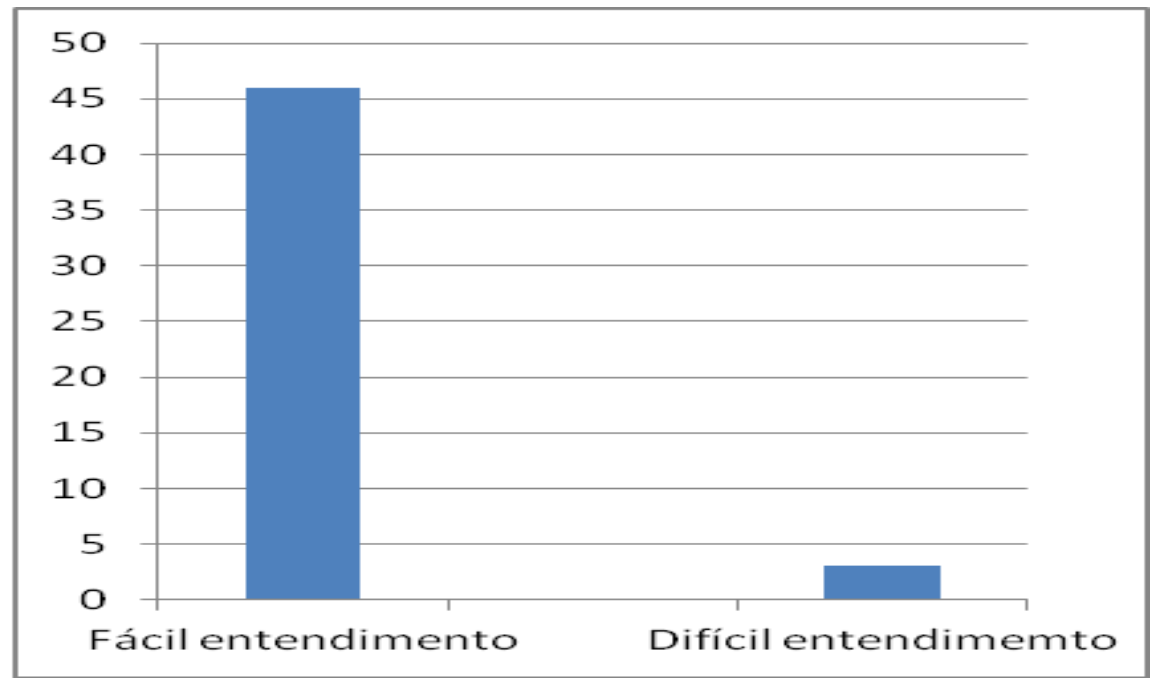

Fonte: Elaborada pelo autor. 2021.

Em relação a assimilação do conteúdo do App, os alunos consideram a

linguagem de fácil compreensão.

Figura 6 - Posse de aparelho de celular

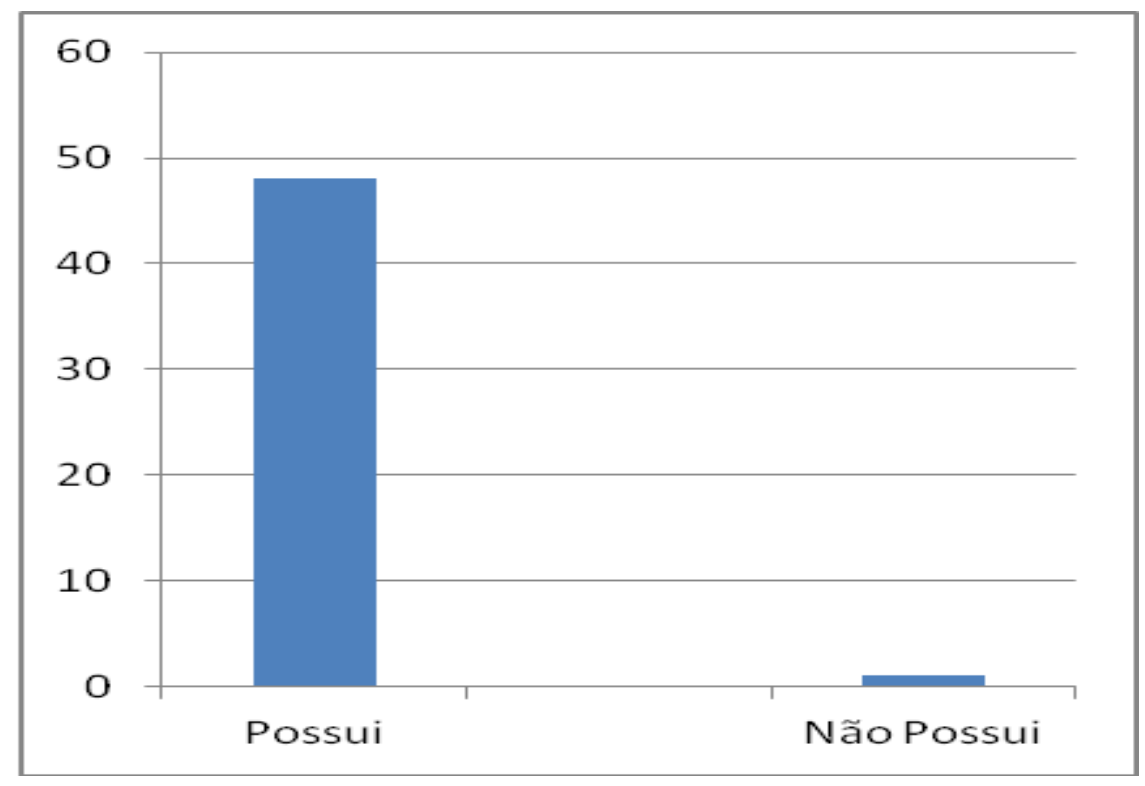

Fonte: Elaborada pelo autor. 2021.

O aparelho celular se tornou uma ferramenta de comunicação e janela para o mundo, 
além do entretenimento que ao mesmo tempo pode ser canal de disseminação do conhecimento.

Figura 7 - Interesse em receber o conteúdo sobre empreendedorismo e inovação em aparelho de celular

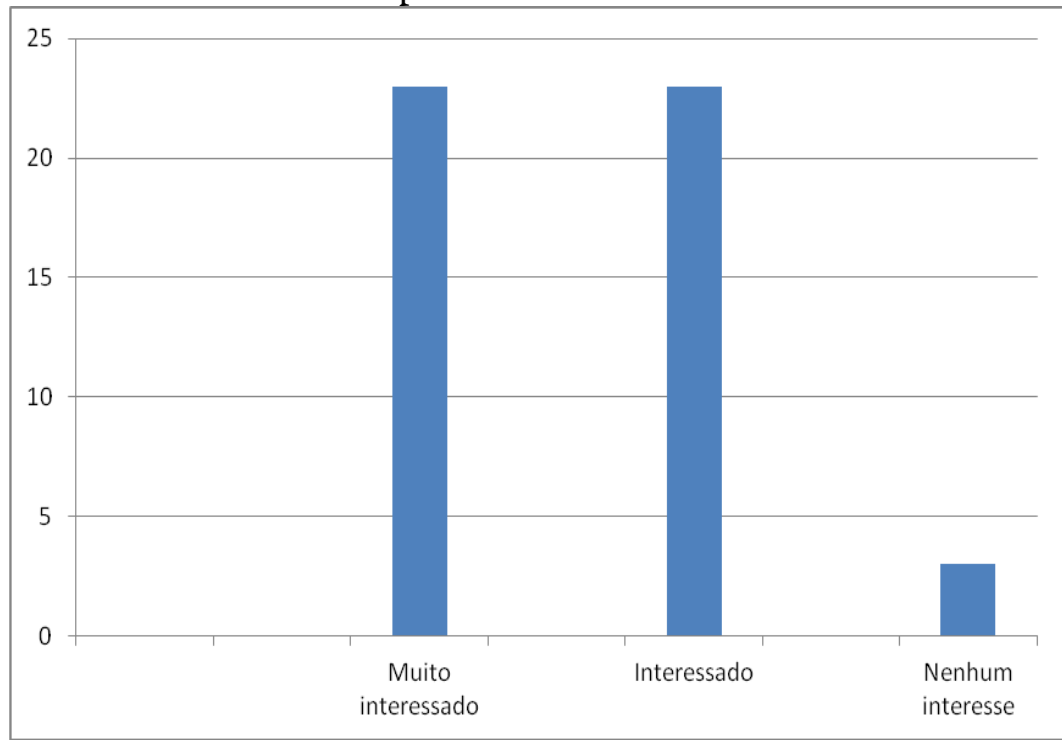

Fonte: Elaborada pelo autor. 202I.

O aluno contemporâneo não vê obstáculo para receber através de um aparelho de celular conteúdo para sua aprendizagem e conhecimento.

Figura 8 - Dificuldade de acesso à rede de internet

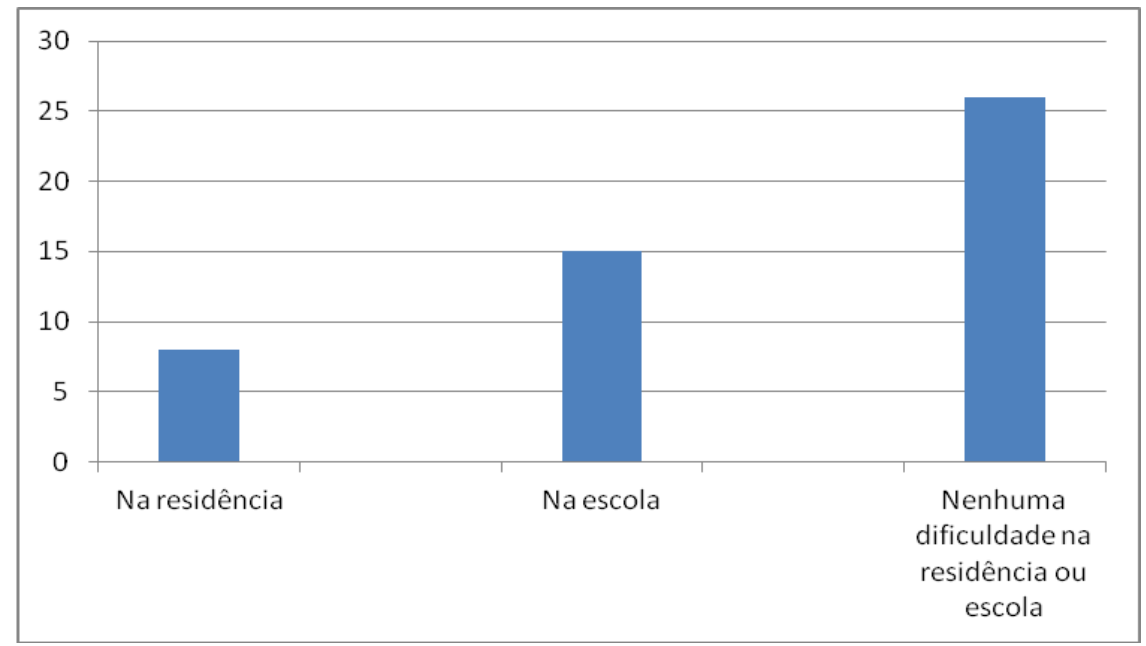

Fonte: Elaborada pelo autor. 2021. 
Uma questão preocupante do aproveitamento do uso do App para o empreendedorismo e a inovação era identificar qual era o nível de dificuldade dos alunos para o acesso a internet. $\mathrm{O}$ resultado então demonstrou que mais de $50 \%$ dos alunos não teriam dificuldade de acesso, podendo ser na escola ou na residência e os demais alunos poderiam acessar apenas a internet em casa ou na escola.

Figura 9 - Relevância sobre o conteúdo do App PROCOMECE

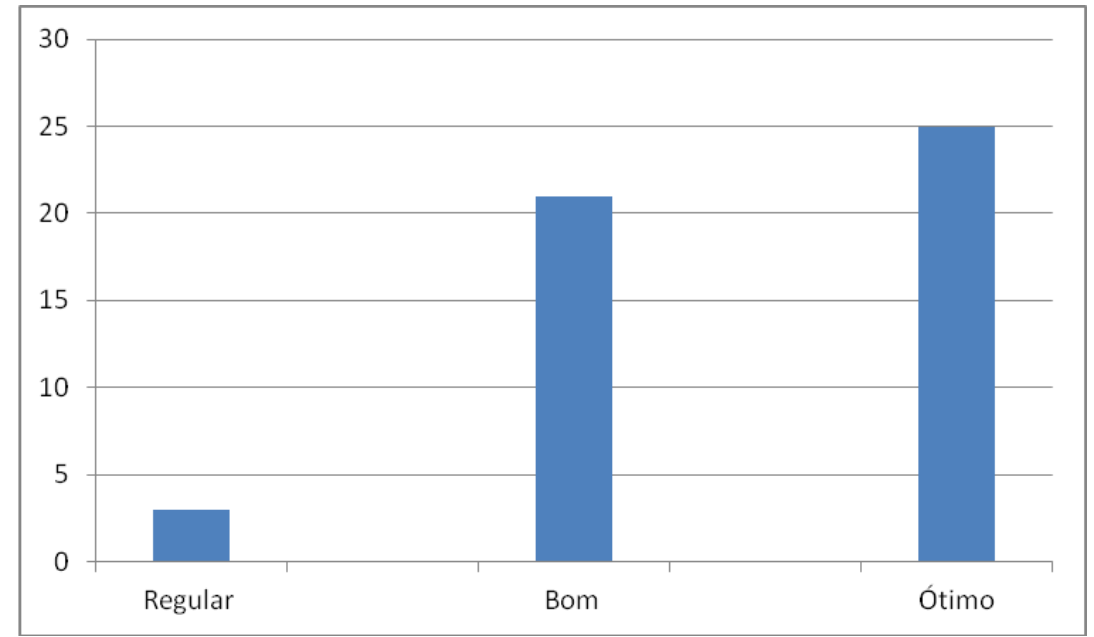

Fonte: Elaborada pelo autor. 2021.

$\mathrm{Na}$ análise quanto a relevância da temática apresentada pelo App PROCOMECE sobre empreendedorismo e inovação, os alunos mesmo não possuindo um conhecimento profundo sobre o tema avaliaram positivamente a oportunidade de busca de informações na área apresentada.

O App PROCOMECE também dispõe da funcionalidade de chat que proporcionará ao usuário o acompanhamento de sua ideação. Também a funcionalidade de cursos e palestras ao vivo, que, agendadas servirão de canais de informação e conhecimento assim como divulgação de eventos e notícias de interesse dos usuários.

O App PROCOMECE se coloca como aliado e parceiro da escola a fim de levar o aluno a ser protagonista da transformação e do desenvolvimento local criando e disseminando a cultura empreendedora e de inovação na educação básica, o que a torna dinâmica, lúdica e prazerosa para a aprendizagem, tendo a escola como 
laboratório de soluções e negócios sociais.

O App PROCOMECE é uma ferramenta eletrônica, com ensino remoto para a formação empreendedora de estudantes. A pesquisa identificou que os estudantes da educação básica desejam e buscam ser agentes e protagonistas de transformação de suas próprias realidades adversas.

\section{I Perfis dos estudantes participantes do estudo}

Participaram da pesquisa cerca de ro estudantes do segmento do ensino médio de escolas públicas de idade de 15 a 18 anos e 49 alunos do $9^{-}$ano do ensino fundamental. Foi analisado o perfil econômico caracterizado de renda familiar de até três salários mínimos.

A pesquisa foi realizada e aplicada de forma presencial. $\mathrm{Na}$ pesquisa foi verificado e constatado o interesse e o conhecimento dos alunos sobre empreendedorismo e inovação, bem como a performance do App.

\section{O empreendedorismo e a inovação como alternativa ao mercado de trabalho}

Dornelas (2014) vê o empreendedorismo mediante a integração de pessoas a processos que resultam na criação de novas ideias para oportunidade de criação de negócios escaláveis. Chiavenato (2012) define o empreendedor como a força que move a economia, mediante alocação de recurso e as suas habilidades e talentos com as ideias dinamizadoras através do conhecimento e estudos.

O empreendedorismo não pode ser tão somente visto como uma nova atividade de trabalho que concebe a ideia da precarização do emprego ou trabalho, assim descrito:

\footnotetext{
O empreendedorismo, na realidade, pode configurar-se como uma nova forma de precarização do trabalho, pois a finalidade de recuperar o padrão de acumulação, reforça a fragilização dos vínculos constituídos na sociedade salarial, o que leva a um fortalecimento do processo de precarização laboral. Esse fenômeno se manifesta de várias formas, sendo fundamental não formarmos uma imagem generalizada dessa atividade. $\mathrm{O}$ empreendedorismo a que nos referimos é aquele onde o sujeito, em geral cercado de possibilidades não favoráveis, vê o empreendimento como único ou melhor investimento, enxergando nessa alternativa a possibilidade de uma vida financeira mais confortável ou como uma possibilidade de subsistência (OLIVEIRA; MOITA; AQUINO. 2016. p.217)
} 
O App PROCOMECE conceitua o usuário em linguagem simples e direta sobre o empreendedorismo, a inovação, a inteligência artificial e as demais formas de negócios como: a) Negócios Gerais - Produz bens e serviços com o objetivo de retorno de investimento mediante as oportunidades e ou necessidades. b) Negócios Sociais - Produz bens e serviços para resolver problema social (missão, impacto e transformação social) com fins lucrativos.

c) Economia Criativa ou Indústria Criativa - Produzem bens e serviços com base no talento e propriedade intelectual, valorização de sua obra ou criação como: diversidade cultural, entretenimento, artesanato, beleza entre outras iniciativas. d) Empreendedorismo Digital (Startup) - Desenvolve um modelo de negócio para oferecer um produto/serviço de tecnologia diferenciado e inovador que é desenvolvido por um aplicativo, plataforma e inteligência artificial. Empreendedorismo Social - Constituído por iniciativas de filantropia, causas e soluções de problemas socioambientais, representadas por ONGs que são organizações da sociedade civil, tendo a sua natureza sem fins lucrativos.

\section{A análise do problema para uma solução inovadora}

A metodologia de problematização segue a etapas da Observação da realidade; Definição dos pontos-chave; Conceituação ou Teorização; Elaboração de hipóteses de solução e a Prática diante da realidade observada.

A metodologia de problematização considera o aluno como uma pessoa ativa e protagonista na produção e construção do conhecimento. O papel do professor é ser mediador, mentor e orientador. Berbel (2012), afirma que a Metodologia da Problematização volta-se para a realização do propósito maior que é preparar o estudante/ser humano para tomar consciência de seu mundo e atuar intencionalmente para transformá-lo, sempre para melhor, para um mundo e uma sociedade que permitam uma vida mais digna para o próprio homem.

O problema é uma situação adversa que incomoda e leva o empreendedor a buscar uma solução. O APP PROCOMECE leva o estudante a analisar e a refletir, sobre o problema que fundamentará a solução a ser criada para resolver uma 
demanda e ou uma necessidade. Existem duas ferramentas próprias para isso: A Árvore de Problemas, que consiste em estudar o problema central influenciado por suas causas e consequências. O Mapa do Problema fará o aprofundamento do problema a ser resolvido, isso é que levará o estudante a verificar as alternativas existentes, a dor do usuário, o problema identificado, o valor gerado e o impacto, conforme figura abaixo:

Figura io - Mapa do Problema

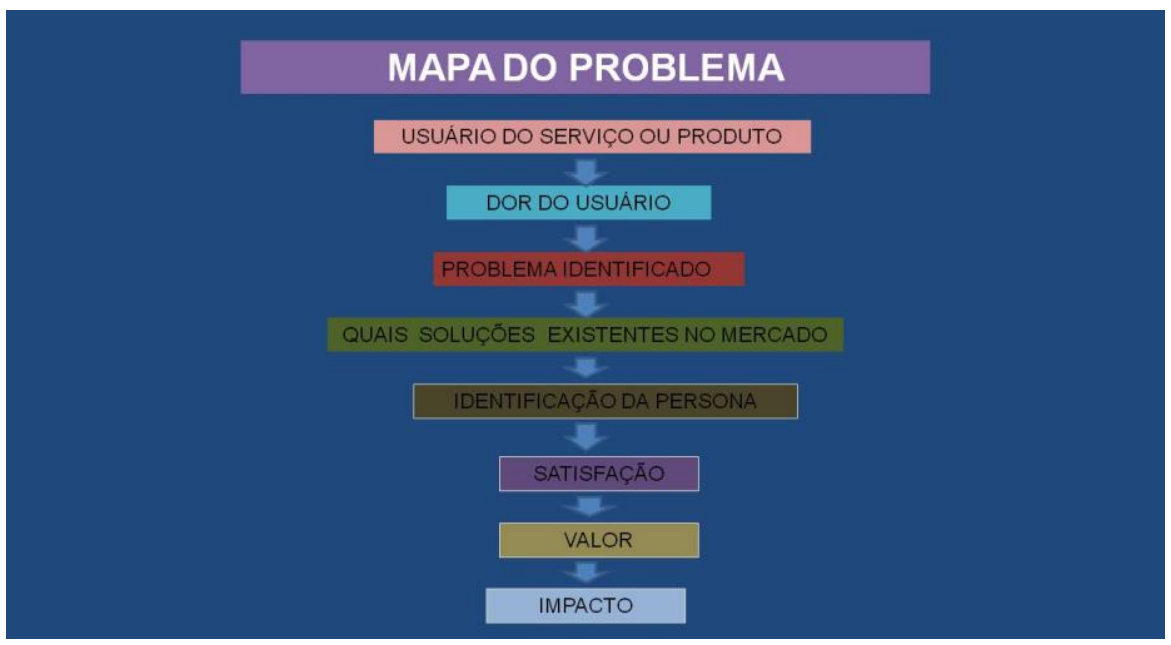

Elaborada pelo autor. 202I.

O aprofundamento do problema leva o usuário do APP PROCOMECE a investigar questões que servirão de base para a melhor ideação ou solução sobre os diversos aspectos de oportunidades para empreender. Este diagnóstico proporciona ao empreendedor a formular e construir projetos inovadores como também fazer a comparação com negócios já existentes de modo a motivá-lo para oportunidades de inovação disruptiva.

Modelo de negócio disruptivo é uma reconfiguração do modelo de negócio existente de uma organização, a fim de adaptar às novas necessidades onde serão oferecidos novos produtos, serviços ou processos (SANTOS; SPECTOR; VAN DER HEYDEN, 2009). 
O usuário é motivado pelo APP PROCOMECE a analisar novas formas de apresentação de serviços e produtos já existentes de modo a aperfeiçoar, contextualizar e adequar às novas exigências e demandas dos consumidores.

(PEREIRA et al., 2015; RODRIGUES et al., 2013).

Após a reflexão e o amadurecimento do problema a ser resolvido o APP PROCOMECE conduz o usuário a pensar na melhor solução através de um negócio com escalabilidade, mas também de impacto socioambiental. A solução precisará produzir algum impacto positivo alinhado aos 17 Objetivos do Desenvolvimento Sustentável, conforme figura abaixo:

Figura II - Objetivos Sustentáveis
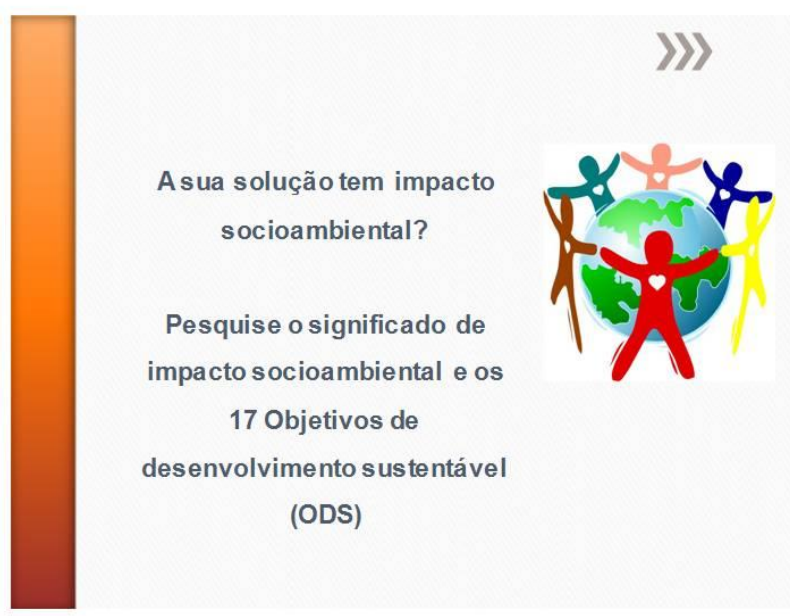

(ODS)

Elaborada pelo autor. 2021.

O App PROCOMECE orienta ao usuário a elaboração de um plano de perguntas direcionadas que o leve a visão da extensão de sua ideia de negócio. Esta planificação de seu negócio permite ao usuário avaliar através de um escopo as possibilidades e os recursos necessários para a efetivação de seu negócio. Verifique a figura abaixo:

O App PROCOMECE estimula o estudante a desenvolver um protótipo de sua solução para verificação da relevância da solução junto ao público alvo ou persona do 
seu produto ou serviço. No final o usuário elabora um Pitch, que é uma apresentação virtual que pode ser apresentado em eventos promovidos pelo App PROCOMECE ou eventos de feiras e exposição de suas ideias na própria escola.

\section{CONSIDERAÇÕES FINAIS}

No dia 30/o9/2021, foi aprovado no Senado Federal o PL 2.944/2021, da senadora Kátia Abreu (PP-TO), que altera a Lei de Diretrizes e Bases da Educação (LDB) para incluir os temas "empreendedorismo" e "inovação" nos currículos da educação básica e superior. Este Projeto de Lei vai de encontro ao objetivo deste estudo que é levar o conhecimento de empreendedorismo e inovação para os estudantes da educação básica.

O autor deste artigo já atuou nos últimos anos como mentor voluntário, através da ABMEN - Associação Brasileira dos Mentores, em dois eventos de Hackathon para estudantes da educação básica. Hackathon é uma maratona de ideação para solução de problema socioambiental que poderá ser caracterizado depois de sua incubação e aceleração, como negócio lucrativo e ao mesmo tempo impacto socioambiental.

Destes eventos participei como mentor voluntário em uma escola privada e outra, realizada em 2019 com mais de 6o alunos do Ensino Médio de dez escolas previamente selecionadas pela Secretaria de Estado de Educação que se reuniram na UERJ para participar do Hackathon Escola Inovadora. Evento organizado por três secretarias estaduais - Secretaria de Ciência, Tecnologia e Inovação, Secretaria de Cultura e Economia Criativa e Secretaria de Educação.

Podemos entender através destas iniciativas, a sociedade nas suas diversas áreas de atuação se movimentando em levar para o segmento da educação básica a implementação do currículo pedagógico aos temas de empreendedorismo e inovação.

O App PROCOMECE tem como propósito entregar ferramentas aos estudantes da educação básica, enfim, instrumentos que os levem a programar eventos que possibilitem criar alternativas de projetos e negócios de impactos positivos. App PROCOMECE será um canal para o estimulo de novas ideias e possibilitando ao mesmo tempo plataforma de informação, notícias, integrando 
escolas, estudantes, investidores e instituições governamentais para a promoção de políticas públicas.

O App PROCOMECE se coloca como aliado e parceiro da escola a fim de levar o aluno a ser protagonista da transformação e do desenvolvimento local criando e disseminando a cultura empreendedora e de inovação na educação básica, o que a torna dinâmica, lúdica e prazerosa para a aprendizagem, tendo a escola como laboratório de soluções e negócios sociais.

O App PROCOMECE é uma ferramenta eletrônica, com ensino remoto para a formação empreendedora de estudantes. A pesquisa identificou que os estudantes da educação básica desejam e buscam ser agentes e protagonistas de transformação de suas próprias realidades adversas.

\section{REFERÊNCIAS}

Berbel NAN. A Metodologia da Problematização em três versões no contexto da didática e da formação de professores. Rev Diálogo Educ.. 2012; 12: 103-20. 2012.

Chiavenato, Idalberto. (2012). Empreendedorismo: dando asas ao espírito empreendedor. São Paulo: Manole.

DElizOICOV, D; ANGOTTI, J. A.; PERNAMBUCO, M. M. Ensino de ciências:fundamentos e métodos. São Paulo: Cortez, 2009.

Dornelas, José. (2014). Empreendedorismo - Transformando Ideias em Negócios. Rio de Janeiro: LTC.

MORAES, G. H. S. M; IIZUKA, E. S; PEDRO, M. Effects of Entrepreneurial Characteristics and University Environment on Entrepreneurial Intention. Revista de Administração Contemporânea, Curitiba , v. 22, n. 2, p. 226-248, Apr. 2018 .

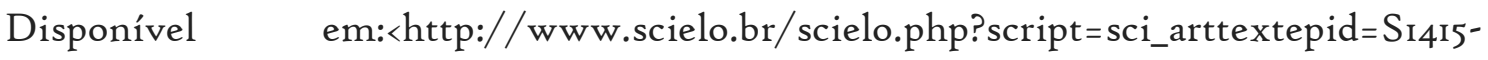
$65552018000200226 \mathrm{elng}=\mathrm{enenrm}=$ iso $>$.Acesso em: 05 Out. 2021.

OLIVEIRA, Eveline Nogueira Pinheiro de; MOITA, Dimitre Sampaio; AQUINO, Cassio Adriano Braz de. O Empreendedor na Era do Trabalho Precário: relações entre empreendedorismo e precarização laboral. Rev. psicol. polít., São Paulo, v. I6, n. 36, p. 207-226, ago. 2016 . Disponível em $<$ http://pepsic.bvsalud.org/scielo.php?script=sci_arttext\&pid=SI519$549 \mathrm{X} 2016000200006 \& \operatorname{lng}=\mathrm{pt} \& \mathrm{nrm}=$ iso $>$. acessos em 05 out. 2021. 
PEREIRA, S. A.; IMBRIZI, F. G.; FreitAS, A. D. G.; AlVARENGA, M. A. Business model as an inducer of disruptive innovations: the case of Gol Airlines. International Journal of Innovation, v. 3, n. 2, p. 28-42, 2015.

ROCHA, E. L. C; FREITAS, A. A. F. Avaliação do ensino de empreendedorismo entre estudantes universitários por meio do perfil empreendedor. Revista de Administração Contemporânea, v. I8, n. 4, p. 465-486, 2014.

RODRIGUES, L. C.; SILVEIRA, A.; MAMORI KONO, C.; LENZI, F. C. Inovação e modelo de negócio - um estudo de caso no setor vitivinicultor. Revista Ibero-Americana de Estratégia, v. I2, n. 2, p. 250-273, 2013.

SEGURA, E.; KALHIL, J. B. A METODOLOGIA ATIVA COMO PROPOSTA PARA O ENSINO DE CIÊNCIAS. REAMEC - Rede Amazônica de Educação em Ciências e Matemática, [S. l.], v. 3, n. I, p. 87-98, 2015. DOI: 10.26571/23186674.a2015.v3.ni.p87-98.i5308. Disponível em: https://dev.setec.ufmt.br/ojs3x/index.php/reamec/article/view/5308. Acesso em: 5 out. 2021. 